\title{
Predictors of antiretroviral therapy initiation: a cross-sectional study among Chinese HIV-infected men who have sex with men
}

Yu Liu', Yuhua Ruan ${ }^{2}$, Sten H. Vermund ${ }^{1,3}$, Chandra Y. Osborn ${ }^{4,5}$, Pingsheng Wu ${ }^{4,6}$, Yujiang Jia', Yiming Shao ${ }^{2}$ and Han-Zhu Qian ${ }^{1,4^{*}}$

\begin{abstract}
Background: Early antiretroviral therapy (ART) initiation is crucial to achieve HIV viral suppression and reduce transmission. HIV-infected Chinese men who have sex with men (MSM) were less likely to initiate ART than other HIV-infected individuals. We assessed predictors of ART initiation among Chinese MSM.

Methods: In 2010-2011, a cross-sectional study was conducted among MSM in Beijing, China. We examined ART initiation within the subgroup who were diagnosed with HIV infection prior to participation in the survey. Logistic regression models were fitted to evaluate socio-demographic and behavioral factors associated with ART initiation. The eligibility criterion in the 2010/2011 national HIV treatment guidelines was CD4 cell count $<350$ cells/ $\mu \mathrm{L}$ or World Health Organization (WHO) clinical stage III/IV.

Results: Of 238 eligible HIV-infected participants, the median duration of HIV infection was 15 months (range: 31 days-12 years); 62 (26.1\%) had initiated ART. Among 103 men with CD4 counts <350 cells/ $\mu$ L, 38 (36.9 \%) initiated ART. Being married to a woman (adjusted odd ratios [aOR]: 2.50; $95 \%$ confidence interval [Cl]: 1.07-5.87), longer duration of HIV infection (aOR: 10.71; 95 \% Cl: 3.66-31.32), and syphilis co-infection (aOR: $2.58 ; 95 \%$ Cl: 1.04-6.37) were associated with a higher likelihood of ART initiation. Of 135 men with CD4 count $\geq 350$ cells/ $\mu \mathrm{L}$, 24 (18\%) initiated ART. Being married to a woman (aOR: 4.21; $95 \%$ Cl: 1.60-11.06), longer duration of HIV infection (aOR: 22.4; 95 \% Cl: 2.79-180), older age (aOR: 1.26; 95 \% Cl: 1.1-1.44), Beijing Hukou (aOR: 4.93; 95 \% Cl: 1.25-19.33), presence of AIDS-like clinical symptoms (aOR: 3.97; $95 \%$ Cl: 1.32-14.0), and history of sexually transmitted infections (aOR: 4.93; $95 \%$ Cl: 1.25-19.43) were associated with ART initiation. Compared with men who did not initiated ART, those with ART were more likely to receive counseling on benefits of ART ( $96.8 \%$ vs. $66.4 \%, P=0<0.01)$, HIV stigma coping strategy (75.8 \% vs. $65.9 \%, P=0.04)$, mental health ( $66.1 \%$ vs. $52.9 \%, P=0.02)$, and substance use ( $46.7 \%$ vs. $36.6 \%, P=0.04)$.
\end{abstract}

Conclusions: We documented low rates of ART initiation among Chinese MSM. Policy changes for expanding ART eligibility and interventions to improve the continuum of HIV care are in progress in China. Impact evaluations can help assess continuing barriers to ART initiation among MSM.

Keywords: HIV, antiretroviral therapy, Continuum of care, Men who have sex with men, China

\footnotetext{
* Correspondence: han-zhu.qian@vanderbilt.edu

'Vanderbilt Institute for Global Health, Vanderbilt University School of

Medicine, Nashville, Tennessee, USA

${ }^{4}$ Department of Medicine, Vanderbilt University School of Medicine,

Nashville, Tennessee, USA

Full list of author information is available at the end of the article
} 


\section{Background}

Antiretroviral therapy (ART) use among HIV-infected individuals is crucial for long-term success in reducing HIV transmission and disease progression [1, 2] Early initiation of ART can suppress viral replication and reduce harmful immune activation, slowing pathogenesis, and stem the spread of the virus ('treatment-as-prevention') [3, 4]. Mathematical modeling and observational studies suggested that the regions with higher ART coverage had reduced HIV transmission between regular and casual sexual partners, lower community viral load, and decreased HIV incidence [5-8]. The randomized clinical trial HPTN052 confirmed that early initiation of ART could significantly reduce sexual transmission of HIV among serodiscordant couples [9].

Despite these benefits of modern ART [2, 8, 10], many HIV-infected individuals in China are still not on ART [11]. A 2011 study showed that only $41 \%(88,185 /$ 214,714) HIV-infected individuals had initiated ART [12], though the rate has been increasing steadily in the recent years. Chinese men who have sex with men (MSM) are less likely to start ART compared with other risk groups [13].

HIV epidemic among Chinese MSM is the most robust in all high risk groups [14-16]. According to the latest national estimates, HIV prevalence among Chinese MSM uniquely represented a marked uptrend (7.3\% in 2013 vs. $0.9 \%$ in 2003), while in other risk groups it either dropped or maintained at a low level [17]. Maleto-male transmission accounted for $21.4 \%$ of all new infections in 2013, with the fastest increasing rate among all risk groups [17]. As Chinese MSM may marry a women due to social and family pressures [18-20], HIVinfected MSM are also likely transmit the virus to their female sexual partner. Therefore, it is a crucial strategy for HIV prevention to expand ART coverage among Chinese MSM. However, there is little knowledge about ART initiation among Chinese MSM. A qualitative study suggested that Chinese MSM may not seek HIV care or initiate ART due to psychological, social, cultural and institutional barriers [21]. We conducted the first quantitative assessment of ART initiation and its predictors among Chinese HIV-infected MSM.

\section{Methods}

\section{Study design and population}

In 2010-2011, we conducted a cross-sectional study among Chinese MSM with a primary objective of assessing the association between male circumcision and HIV risk among MSM in Beijing, China. This study was described elsewhere [22-24]. In brief, participants were recruited from HIV/sexually transmitted disease (STD) clinics or the community, and through peer-referral; participants who were tested HIV positive from other studies in Beijing were also recruited. Eligibility criteria included: being a male, living in Beijing, self-reporting ever having sex with men, willingness to provide blood samples for HIV and syphilis serological tests and anal swab specimens for HPV testing, and willingness to provide written informed consent were eligible to participate in the study. All eligible participants were asked to complete a questionnaire interview, undertake genital examinations, and provide blood samples [24]. The study protocol was approved by the Institutional Review Boards of the National Center for AIDS/STD Control and Prevention of the Chinese Center for Disease Control and Prevention, and the Vanderbilt University School of Medicine.

\section{Data collection}

Each participant completed a questionnaire on sociodemographic characteristics: age, ethnicity, marital status, education, occupation, registered household in Beijing (or Beijing Hukou), duration of living in Beijing, and sexual orientation. The questionnaire also assessed behavioral risk factors: unprotected insertive or receptive anal sex, most recent $\mathrm{CD} 4+$ T-lymphocyte cell count (CD4+ count), and history of sexually transmitted diseases (STD, including chlamydia, gonorrhea, syphilis, herpes simplex type 2, etc.). Those who had been diagnosed with HIV infection prior to participation in this study were also asked about AIDS-like clinical symptoms, experiences of using ART and HIV care and counseling, such as substance use, mental health, stigma coping strategies, benefits of ART, and prevention of HIV transmission.

\section{Laboratory testing}

Enzyme-linked immunosorbent assay (ELISA, Wantai Biological Medicine Company, Beijing, China) was used for HIV-1 screening. Positive samples were confirmed by HIV-1/2 Western blot (HIV Blot $2.2 \mathrm{WB}^{\mathrm{rm}}$; Genelabs Diagnostics, Singapore). Syphilis serology was determined through rapid plasma reagin (RPR, Shanghai Kehua Biotechnology Ltd, China) and confirmed by Treponema pallidum Enzyme-linked immunosorbent assay (TP-ELISA, Beijing Wantai Biological Pharmacy Enterprise Co., Ltd, China)[24].

\section{Statistical analysis}

A significant portion of participants had been previously diagnosed with HIV infection, and were asked for ART use. Therefore, we performed a subgroup analysis among these participants to assess their ART initiation and its predictor variables.

We expressed descriptive statistics as proportions for categorical variables and as means and standard deviations, or medians and interquartile ranges for continuous variables, depending on the distribution of the variables. 
Table 1 Sociodemographic and behavioral characteristics of HIV-infected men who have sex with men in Beijing, China

\begin{tabular}{|c|c|c|c|c|}
\hline \multirow[b]{2}{*}{ Characteristic } & \multirow[b]{2}{*}{ Total sample $(\mathrm{N}=238), \mathrm{n}(\%)$} & \multicolumn{2}{|c|}{ Having initiated ART } & \multirow[b]{2}{*}{$P$-value } \\
\hline & & Yes $(\mathrm{N}=62), \mathrm{n}(\%)$ & No $(\mathrm{N}=176), \mathrm{n}(\%)$ & \\
\hline Age, median (IQR) (year) & $31(26-37)$ & $36(31-42)$ & $30(26-35)$ & $<0.001$ \\
\hline Ethnicity & & & & 0.69 \\
\hline Han & $224(94.1)$ & $59(95.2)$ & $165(93.7)$ & \\
\hline Others & $13(5.9)$ & $3(4.8)$ & $6.3(6.3)$ & \\
\hline Marital status & & & & $<0.001$ \\
\hline Currently unmarried & $170(71.4)$ & $31(50.0)$ & $139(79.0)$ & \\
\hline Currently married & $68(28.6)$ & $31(50.0)$ & $37(21.0)$ & \\
\hline Education (year of schooling) & & & & 0.78 \\
\hline College or above (>12) & $128(53.8)$ & $31(50.0)$ & $97(55.1)$ & \\
\hline Senior high school (10-12) & $69(29.0)$ & $18(29.1)$ & $51(29.0)$ & \\
\hline Junior high school (7-9) & $34(14.3)$ & $11(17.7)$ & $23(13.1)$ & \\
\hline Primary school $(<=6)$ & $7(2.9)$ & $2(3.2)$ & $5(2.8)$ & \\
\hline Occupational status & & & & 0.27 \\
\hline Employed & $178(74.8)$ & $47(75.8)$ & $131(74.4)$ & \\
\hline Non-employed/retired & $34(14.3)$ & $12(19.4)$ & $22(12.5)$ & \\
\hline Student & $10(4.2)$ & $1(1.6)$ & $9(5.1)$ & \\
\hline Other & $16(6.7)$ & $2(3.2)$ & $14(8.0)$ & \\
\hline Beijing Hukou & & & & 0.003 \\
\hline No & $91(38.2)$ & $14(22.6)$ & $77(43.7)$ & \\
\hline Yes & $147(61.8)$ & $48(77.4)$ & $99(56.3)$ & \\
\hline Duration of living in Beijing (year) & & & & 0.008 \\
\hline$<5$ & 99 (41.6) & $17(27.4)$ & $82(46.6)$ & \\
\hline$\geq 5$ & $139(58.4)$ & $45(72.6)$ & $94(53.4)$ & \\
\hline Time from HIV infection to survey (month) & & & & 0.001 \\
\hline$<15$ & $115(48.3)$ & $6(9.7)$ & $109(61.9)$ & \\
\hline$\geq 15$ & $123(51.7)$ & $56(90.3)$ & $67(38.1)$ & \\
\hline Self-report health condition & & & & 0.91 \\
\hline Very good/good & $193(81.1)$ & $50(80.6)$ & $143(81.3)$ & \\
\hline Somewhat poor/very poor & $45(18.9)$ & $12(19.4)$ & $33(18.7)$ & \\
\hline Ever had AIDS-like clinical symptoms ${ }^{a}$ & & & & 0.02 \\
\hline No & $177(74.4)$ & $39(62.9)$ & $138(78.4)$ & \\
\hline Yes & $61(25.6)$ & $23(37.1)$ & $38(21.6)$ & \\
\hline Had unprotected insertive anal sex with men in past 6 months & & & & 0.004 \\
\hline No & $77(71.3)$ & $21(95.5)$ & $56(65.1)$ & \\
\hline Yes & $31(28.7)$ & $1(4.5)$ & $30(34.9)$ & \\
\hline Had unprotected receptive anal sex with men in past 6 months & & & & $<0.001$ \\
\hline No & $86(64.7)$ & $27(93.1)$ & $59(56.7)$ & \\
\hline Yes & $47(35.3)$ & $2(6.9)$ & $45(43.6)$ & \\
\hline Had multiple concurrent male partners in past 12 months & & & & 0.60 \\
\hline No & $211(90.9)$ & $57(93.4)$ & $154(90.1)$ & \\
\hline Yes & $21(9.1)$ & $4(6.6)$ & $17(9.9)$ & \\
\hline
\end{tabular}


Table 1 Sociodemographic and behavioral characteristics of HIV-infected men who have sex with men in Beijing, China (Continued)

\begin{tabular}{llll}
\hline Had commercial sex in past 12 months & & & \\
No & $220(94.4)$ & $60(96.8)$ & $160(93.6)$ \\
Yes & $13(5.6)$ & $2(3.2)$ & $11(6.4)$ \\
History of sexually transmitted diseases & & & 0.52 \\
No & $100(44.4)$ & $17(28.3)$ & $83(50.3)$ \\
Yes & $125(55.6)$ & $43(71.7)$ & $82(49.7)$ \\
Syphilis co-infection & & $15(24.2)$ & $78(44.3)$ \\
No & $93(39.1)$ & $47(75.8)$ & $98(55.7)$ \\
Yes & $145(60.9)$ & 0.003
\end{tabular}

Note: Sample size for each variable may vary due to missing data; IQR interquartile range, $A R T$ antiretroviral therapy

${ }^{a}$ Ever had at least one of these adverse clinical symptoms in the past 6 months: severe weight loss ( $\left.>10 \%\right)$, fever ( $>1$ month, continuing or intermittent), chronic diarrhea (>1 month), severe bacterial infection (e.g. pneumonia), oral candidiasis, oral leukoplakia, tuberculosis other stage III or stage IV symptoms

The socio-demographic, clinical, and behavioral characteristics were compared between those who had initiated ART and who had not in the whole study sample and in subgroups by CD4 count of 350 cells/uL, which was the cut point of ART eligibility in Chinese national guidelines during 2010 and 2011.We also examined WHO HIV clinical staging (III or IV) for dividing the subgroups. Continuous variables were compared with Wilcoxon ranksum tests, and categorical variables were compared with the Chi-square or Fisher's exact tests. Proportions of MSM receiving HIV care counseling services between men who did and did not initiate ART were compared using Chisquare tests.

To further assess the strength and direction of the associations between selected predictors and ART initiation stratified by $\mathrm{CD} 4+$ count, variables moderately associated with ART initiation $(P<0.2)$ in bivariable analyses were selected for multivariable logistic regression analyses. In the multivariable logistic regression models, variables with a $P<0.2$ in the bivariable logistic regression analyses were preliminarily fitted into each model, respectively, then a manual backward selection procedure was used to conclude the final multivariable models that only retained covariates significantly associated with the outcome $(P<0.05)$. However, factors considered as a priori predictors or confounders based on prior evidence were forced to retain in the final models regardless of $P$-value [25]. All statistical analyses were performed using Stata 12.0 ${ }^{\text {im }}$ (StataCorp LP, College Station, Texas, USA).

\section{Results}

\section{Characteristics of Study Population}

Among 1155 participants in the study, 290 were confirmed to be HIV positive (25.1\%), including 48 men newly diagnosed upon enrolled in the current study and 242 previously diagnosed. The 48 newly diagnosed HIV cases were excluded in the analysis since they had had no opportunity to initiate ART upon the survey. Of the 242 previously diagnosed HIV-infected MSM, 4 had missing data on ART initiation, and therefore, 238 $(98.3 \%)$ were included in this analysis.

The median age of these 238 men was 31 years (interquartile range [IQR], 26-37) and median duration from HIV diagnosis to participation in this survey was 15 months (IQR, 6-31).A majority of participants were Han ethnics (94.1\%), were currently unmarried (71.4\%) and employed (74.8\%), had college education (53.8\%), and had Beijing Hukou (61.8\%).

Over a quarter (26.1 \%) men had started ART. Compared with those who had not initiated ART, men who had initiated ART were more likely $(P<0.05)$ to be older, be married to a woman, have Beijing Hukou, live longer in Beijing, have a longer duration of HIV-infection, experience adverse clinical symptoms, have a history of STD, and be co-infected with syphilis. However, those who had initiated ART were less likely $(P<0.05)$ to be engaged in unprotected insertive or receptive anal sex (Table 1).

Among 103 MSM with CD4 + cell count (CD4 count $)<350$ cells $/ \mu \mathrm{L}$ who met the eligibility criteria for Chinese free ART program during this survey, $36.7 \%$ initiated ART. Those who had initiated ART were more likely $(P<0.05)$ to be married to a woman, have longer duration of HIV-infection, and have syphilis coinfection, but were less likely $(P<0.05)$ to have unprotected insertive or receptive anal sex (Table 2 ).

Of 135 MSM with CD4 count $\geq 350$ cells/ $\mu \mathrm{L}$ who did not meet the criteria, $17.8 \%$ initiated ART. Those who had initiated ART were more likely $(P<0.05)$ to be older, married to a woman, have Beijing $\mathrm{Hukou}$, live longer in Beijing, have longer duration of HIV-infection, have ever had clinical symptoms, have a history of STD, and have syphilis co-infection, but were less likely $(P<0.05)$ to have unprotected insertive or receptive anal sex (Table 2 ).

Factors associated with ART initiation by CD4 count level Table 3 shows the variables associated with ART initiation in both bivariable and multivariable logistic regression 
Table 2 Sociodemographic and behavioral characteristics of HIV-infected men who have sex with men by CD4 count in Beijing, China

\begin{tabular}{|c|c|c|c|c|c|c|c|c|}
\hline \multirow[b]{2}{*}{ Characteristics } & \multicolumn{4}{|c|}{ CD4 count $<350$ cells $/ \mu \mathrm{L}^{\mathrm{a}}$} & \multicolumn{4}{|c|}{ CD4 count $\geq 350$ cells $/ \mu \mathrm{L}$} \\
\hline & $\begin{array}{l}\text { Total } \\
(\mathrm{N}=103), \\
\mathrm{n}(\%)\end{array}$ & $\begin{array}{l}\text { Initiated } \\
\text { ART(N=38), } \\
n(\%)\end{array}$ & $\begin{array}{l}\text { Not initiated } \\
\text { ART(N=65), } \\
n(\%)\end{array}$ & $P$-value & $\begin{array}{l}\text { Total } \\
(\mathrm{N}=135), \\
\mathrm{n}(\%)\end{array}$ & $\begin{array}{l}\text { Initiated ART } \\
(\mathrm{N}=24) \text {, } \\
\mathrm{n}(\%)\end{array}$ & $\begin{array}{l}\text { Not initiated ART } \\
(\mathrm{N}=111), \\
\mathrm{n}(\%)\end{array}$ & $P$-value \\
\hline Age (year) & & & & 0.07 & & & & $<0.001$ \\
\hline Median, IQR & $32(27-38)$ & $34(29-39)$ & $30(26-36)$ & & $31(26-37)$ & $41(35-45)$ & $30(25-34)$ & \\
\hline Ethnicity & & & & 1.00 & & & & 0.59 \\
\hline Han & $95(92.2)$ & $35(92.1)$ & $60(92.3)$ & & $129(95.6)$ & $24(100.0)$ & 105 (94.6) & \\
\hline Non-Han & $8(7.8)$ & $3(7.9)$ & $5(7.7)$ & & $6(4.4)$ & $0(0)$ & $6(5.4)$ & \\
\hline Marital status & & & & 0.03 & & & & $<0.001$ \\
\hline Currently unmarried & $68(66.0)$ & $20(52.6)$ & $48(73.8)$ & & $102(75.6)$ & $11(45.8)$ & $91(82.0)$ & \\
\hline Currently married & $35(34.0)$ & $18(47.4)$ & $17(26.2)$ & & $33(24.4)$ & $13(54.2)$ & $20(18.0)$ & \\
\hline Education (year of schooling) & & & & 0.92 & & & & 0.52 \\
\hline College or above $(>12)$ & $57(55.3)$ & $21(55.2)$ & $36(55.4)$ & & $71(52.6)$ & $10(41.7)$ & $61(55.0)$ & \\
\hline Senior high school (10-12) & $24(23.3)$ & $8(21.1)$ & $16(24.6)$ & & $45(33.3)$ & $10(41.7)$ & $35(31.5)$ & \\
\hline Junior high school (7-9) & $19(18.5)$ & $8(21.1)$ & $11(16.9)$ & & $15(11.1)$ & $3(12.5)$ & $12(10.8)$ & \\
\hline Primary school $(\leq 6)$ & $3(2.9)$ & $1(2.6)$ & $2(3.1)$ & & $4(3.0)$ & $1(4.1)$ & $3(2.7)$ & \\
\hline Occupational status & & & & 0.87 & & & & 0.39 \\
\hline Employed & $81(78.6)$ & 31 (81.6) & $50(76.9)$ & & $97(71.8)$ & $16(66.6)$ & $81(73.0)$ & \\
\hline Non-employed/retired & $15(14.6)$ & $5(13.2)$ & $10(15.4)$ & & $19(14.1)$ & $7(29.2)$ & $12(10.8)$ & \\
\hline Student & $2(1.9)$ & $1(2.6)$ & $1(1.5)$ & & $8(5.9)$ & $0(0)$ & $8(7.2)$ & \\
\hline Other & $5(4.9)$ & $1(2.6)$ & $4(6.2)$ & & $11(8.2)$ & $1(4.2)$ & $10(9.0)$ & \\
\hline Beijing Hukou & & & & 0.19 & & & & $<0.001$ \\
\hline No & $39(37.9)$ & $11(28.9)$ & $28(43.1)$ & & $52(38.5)$ & $3(12.5)$ & $49(44.1)$ & \\
\hline Yes & $64(62.1)$ & $27(71.1)$ & $37(56.9)$ & & $83(61.5)$ & $21(87.5)$ & $62(55.9)$ & \\
\hline $\begin{array}{l}\text { Duration of living in Beijing } \\
\text { (year) }\end{array}$ & & & & 0.06 & & & & 0.04 \\
\hline$<5$ & $45(43.7)$ & $12(31.6)$ & $33(50.8)$ & & $54(40.0)$ & $5(20.8)$ & $49(44.1)$ & \\
\hline$\geq 5$ & $58(56.3)$ & $26(68.4)$ & $32(49.2)$ & & $81(60.0)$ & $19(79.2)$ & $62(55.9)$ & \\
\hline $\begin{array}{l}\text { Time from HIV infection to } \\
\text { survey (month) }\end{array}$ & & & & $<0.001$ & & & & $<0.001$ \\
\hline$<15$ & $46(44.7)$ & $5(13.2)$ & $41(63.1)$ & & $69(51.1)$ & $1(4.2)$ & $68(61.3)$ & \\
\hline$\geq 15$ & $57(55.3)$ & $33(86.8)$ & $24(36.9)$ & & $66(48.9)$ & $23(95.8)$ & $43(38.7)$ & \\
\hline Self-report health condition & & & & 1.00 & & & & 0.53 \\
\hline Very good/good & $77(74.8)$ & $28(73.7)$ & $49(75.4)$ & & $116(85.9)$ & $22(91.7)$ & $94(84.7)$ & \\
\hline Somewhat poor/very poor & $26(25.4)$ & $10(26.3)$ & $16(24.6)$ & & $19(14.1)$ & $2(8.3)$ & $17(15.3)$ & \\
\hline $\begin{array}{l}\text { Ever had AIDS-like clinical } \\
\text { symptoms }{ }^{\mathrm{b}}\end{array}$ & & & & 0.35 & & & & 0.02 \\
\hline No & $77(74.8)$ & $26(68.4)$ & $51(78.5)$ & & $100(74.1)$ & $13(54.2)$ & $87(78.4)$ & \\
\hline Yes & $26(25.2)$ & $12(31.6)$ & $14(21.5)$ & & $35(25.9)$ & $11(45.8)$ & $24(21.6)$ & \\
\hline $\begin{array}{l}\text { Had unprotected insertive anal } \\
\text { sex with men in past } 6 \text { months }\end{array}$ & & & & 0.02 & & & & 0.25 \\
\hline No & $34(79.1)$ & $14(100)$ & $20(69.0)$ & & $43(66.2)$ & $7(87.5)$ & $36(63.2)$ & \\
\hline Yes & $9(20.9)$ & $0(0)$ & $9(31.0)$ & & $22(33.8)$ & $1(12.5)$ & $21(36.8)$ & \\
\hline $\begin{array}{l}\text { Had unprotected receptive anal } \\
\text { sex with men in past } 6 \text { months }\end{array}$ & & & & 0.04 & & & & 0.01 \\
\hline
\end{tabular}


Table 2 Sociodemographic and behavioral characteristics of HIV-infected men who have sex with men by CD4 count in Beijing, China (Continued)

\begin{tabular}{|c|c|c|c|c|c|c|c|c|}
\hline No & $43(75.4)$ & $16(94.1)$ & $27(67.5)$ & & $43(56.6)$ & $11(91.7)$ & $32(50.0)$ & \\
\hline Yes & $14(24.6)$ & $1(5.9)$ & $13(32.5)$ & & $33(43.4)$ & $1(8.3)$ & $32(50.0)$ & \\
\hline $\begin{array}{l}\text { Had multiple concurrent male } \\
\text { partners in past } 12 \text { months }\end{array}$ & & & & 0.71 & & & & 1.00 \\
\hline No & $93(93.0)$ & $36(94.7)$ & $57(91.9)$ & & $118(89.4)$ & $21(91.3)$ & $97(89.0)$ & \\
\hline Yes & $7(7.0)$ & $2(5.3)$ & $5(8.1)$ & & $14(10.6)$ & $2(8.7)$ & $12(11.0)$ & \\
\hline $\begin{array}{l}\text { Had commercial sex in past } 12 \\
\text { months }\end{array}$ & & & & 1.00 & & & & 0.35 \\
\hline No & $94(94.0)$ & $36(94.7)$ & $58(93.6)$ & & $126(94.7)$ & $24(100.0)$ & $102(93.6)$ & \\
\hline Yes & $6(6.0)$ & $2(5.3)$ & $4(6.4)$ & & $7(5.3)$ & $0(0)$ & $7(6.4)$ & \\
\hline $\begin{array}{l}\text { History of sexually transmitted } \\
\text { diseases }\end{array}$ & & & & 0.30 & & & & 0.003 \\
\hline No & $43(43.0)$ & $13(35.1)$ & $30(47.6)$ & & $57(45.6)$ & $4(17.4)$ & $53(52.0)$ & \\
\hline Yes & $57(57.0)$ & $24(64.9)$ & $33(52.4)$ & & $68(54.4)$ & $19(82.6)$ & $49(48.0)$ & \\
\hline Syphilis co-infection & & & & 0.03 & & & & 0.11 \\
\hline No & 39 (37.9) & $9(23.7)$ & $30(46.2)$ & & $54(40.0)$ & $6(25.0)$ & $48(43.2)$ & \\
\hline Yes & $64(62.1)$ & $29(76.3)$ & $35(53.8)$ & & $81(60.0)$ & $18(75.0)$ & $63(56.8)$ & \\
\hline
\end{tabular}

Note: Sample size for each variable may reduce due to missing data; IQR inter quartile range ${ }^{a} \mathrm{CD} 4$ count $<350$ cells/ $\mu \mathrm{L}$ was eligible for free antiretroviral therapy at the time of the study

${ }^{b}$ Ever had at least one of these adverse clinical symptoms in the past 6 months: severe weight loss (>10\%), fever (>1 month, continuing or intermittent), chronic diarrhea (>1 month), severe bacterial infection (e.g. pneumonia), oral candidiasis, oral leukoplakia, tuberculosis other stage III or stage IV symptoms

analyses. In the final multivariable logistic regression models, being married (adjusted odd ratio [aOR]: 2.50; $95 \%$ confidence interval [CI]: 1.07-5.87), longer duration of HIV infection (aOR: 10.7; $95 \%$ CI: 3.66-31.3), and syphilis co-infection (aOR: 2.58 ; 95 \% CI: 1.04-6.37) were associated with a higher likelihood of ART initiation among subgroup of CD4 count $<350$ cells/uL. Being married (aOR: 4.21; 95 \% CI: 1.60-11.06), longer duration of HIV infection (aOR: 22.42; 95 \% CI: 2.79-180.01), older age (aOR: 1.26; 95 \% CI: 1.1-1.44), Beijing Hukou (aOR: 4.93; 95 \% CI: 1.25-19.33), presence of AIDS-like clinical symptoms (aOR: 3.97; 95 \% CI: 1.32-14.0), and prior STD (aOR: 4.93; 95 \% CI: $1.25-19.43)$ were associated with a higher likelihood of ART initiation among subgroup of CD4 count $\geq 350$ cells/uL.

\section{HIV care counseling services received}

The top three HIV care counselling received by the participants were HIV transmission prevention (78.6\%), benefits of ART (66.4\%), and HIV stigma coping strategy (65.6\%). Other counseling topics included mental health (52.9\%), nutrition (41.2\%), substance abuse (36.6\%), and birth control (25.6 \%) (Fig. 1). MSM who initiated ART were more likely to receive counseling than those without ART on benefits of ART ( $96.8 \%$ vs. $66.4 \%, P<0.01)$, HIV stigma coping strategy $(75.8 \%$ vs. $65.9 \%, P=0.04)$, substance use ( $46.7 \%$ vs. $36.6 \%, P=0.04)$, and mental health (66.1 \% vs. $52.9 \%, P=0.02$ ). There was no statistically significant difference in receiving counseling on HIV transmission prevention, birth control, and nutrition between those who had or had not initiated ART.

\section{Discussion}

To our knowledge, this is the first study on predictors of ART initiation and receipt of HIV care among Chinese HIV-infected MSM. In the study, we found older age and ever having adverse clinical symptoms were positively associated with ART initiation, and this is consistent with findings from other regions [26]. Due to social and family pressure, some Chinese MSM are married with women or have female sexual partners [27]. Our study showed that married MSM were more likely to start ART than unmarried MSM. Married men might have more sense of responsibility for the health of themselves and their wives, and therefore have started ART; however, more research is needed to explore the reasons. Beijing Hukou and longer duration of living in Beijing were also positively associated with ART initiation. Migrant MSM, particularly recent migrants, might not know that free ART is for everyone, or where they could get it. It is suggested HIV intervention programs should give special emphasis among migrant MSM who account for the majority of MSM population in many large cities. In addition, Men who had initiated ART reported receiving more HIV care counseling services than those without ART, and therefore could get more health benefits from the counseling.

Our findings suggest considerations for the design of future intervention programs. The positive association 
Table 3 Bivariable and multivariable logistic regression analyses of factors associated with initiation of antiretroviral therapy among HIV-infected men who have sex with men by CD4 count in Beijing, China

\begin{tabular}{|c|c|c|c|c|c|c|}
\hline \multirow[b]{2}{*}{ Factors } & \multicolumn{3}{|c|}{ CD4 count $<350$ cells $/ \mu \mathrm{L}(\mathrm{n}=103)^{\mathrm{a}}$} & \multicolumn{3}{|c|}{ CD4 count $\geq 350$ cells/ $\mu \mathrm{L}(\mathrm{n}=135)$} \\
\hline & $\begin{array}{l}\text { Initiated } \\
\text { ART, \% } \\
(n=38)\end{array}$ & $\begin{array}{l}\text { Crude OR } \\
(95 \% \mathrm{Cl})\end{array}$ & $\begin{array}{l}\text { Adjusted OR } \\
(95 \% \mathrm{Cl})\end{array}$ & $\begin{array}{l}\text { Initiated } \\
\text { ART, \% } \\
(n=24)\end{array}$ & Crude OR (95 \% Cl) & $\begin{array}{l}\text { Adjusted OR } \\
(95 \% \mathrm{Cl})\end{array}$ \\
\hline Age in years; Median (IQR) & $34(29-39)$ & $1.04(0.99,1.09)^{*}$ & $1.02(0.96,1.09)$ & $41(35-45)$ & $1.18(1.10,1.27)^{* * *}$ & $1.26(1.11,1.44)^{* * *}$ \\
\hline \multicolumn{7}{|l|}{ Marital status } \\
\hline Currently unmarried & 29.4 & 1.00 & 1.00 & 10.8 & 1.00 & 1.00 \\
\hline Currently married & 51.4 & $2.54(1.09,5.91)^{* *}$ & $2.50(1.07,5.87)^{* *}$ & 39.4 & $5.38(2.11,13.73)^{* * *}$ & $4.21(1.60,11.06)^{* * *}$ \\
\hline \multicolumn{7}{|l|}{ Beijing Hukou } \\
\hline No & 28.2 & 1.00 & 1.00 & 5.8 & 1.00 & 1.00 \\
\hline Yes & 42.2 & $1.86(0.79,4.37)^{*}$ & $2.02(0.74,5.50)$ & 25.3 & $5.53(1.56,19.63)^{* * *}$ & $4.93(1.25,19.33)^{* *}$ \\
\hline \multicolumn{7}{|c|}{ Duration of living in Beijing (year) } \\
\hline$<5$ & 26.7 & 1.00 & 1.00 & 9.3 & 1.00 & 1.00 \\
\hline$\geq 5$ & 44.8 & $2.23(0.96,5.17)^{*}$ & $1.91(0.77,4.75)$ & 23.5 & $3.00(1.05,8.61)^{* *}$ & $1.98(0.28,14.04)$ \\
\hline \multicolumn{7}{|c|}{$\begin{array}{l}\text { Time from HIV infection to survey } \\
\text { (month) }\end{array}$} \\
\hline$<15$ & 10.9 & 1.00 & 1.00 & 1.5 & 1.00 & 1.00 \\
\hline$\geq 15$ & 57.9 & $11.28(3.88,32.78)^{* * *}$ & $10.71(3.66,31.32)^{* * *}$ & 34.9 & $36.37(4.74,279.22)^{* * *}$ & $22.4(2.79,180.01)^{* * *}$ \\
\hline \multicolumn{7}{|l|}{$\begin{array}{l}\text { Ever had AIDS-like clinical } \\
\text { symptoms }\end{array}$} \\
\hline No & 33.8 & & & 13.0 & 1.00 & 1.00 \\
\hline Yes & 46.2 & NS & NS & 31.4 & $3.07(1.22,7.71)^{* *}$ & $3.97(1.32,13.96)^{* *}$ \\
\hline \multicolumn{7}{|c|}{$\begin{array}{l}\text { Had unprotected insertive anal sex } \\
\text { with men in past } 6 \text { months }\end{array}$} \\
\hline No & 41.2 & 1.00 & 1.00 & 16.3 & & \\
\hline Yes & 0 & - & - & 4.6 & NS & NS \\
\hline \multicolumn{7}{|c|}{$\begin{array}{l}\text { Had unprotected receptive anal } \\
\text { sex with men in past } 6 \text { months }\end{array}$} \\
\hline No & 37.2 & 1.00 & 1.00 & 25.6 & 1.00 & 1.00 \\
\hline Yes & 7.1 & $0.13(0.02,1.09)^{*}$ & $0.22(0.02,2.13)$ & 3.0 & $0.09(0.01,0.75)^{* *}$ & $0.11(0.01,1.40)$ \\
\hline \multicolumn{7}{|c|}{$\begin{array}{l}\text { History of sexually transmitted } \\
\text { diseases }\end{array}$} \\
\hline No & 30.2 & & & 7.0 & 1.00 & 1.00 \\
\hline Yes & 42.1 & NS & NS & 27.9 & $5.14(1.63,16.16)^{* * *}$ & $4.93(1.25,19.43)^{* *}$ \\
\hline \multicolumn{7}{|l|}{ Syphilis co-infection } \\
\hline No & 23.1 & 1.00 & 1.00 & 11.1 & 1.00 & 1.00 \\
\hline Yes & 45.3 & $2.76(1.13,6.74)^{* *}$ & $2.58(1.04,6.37)^{* *}$ & 22.2 & $2.29(0.84,6.20)^{*}$ & $1.39(0.41,4.72)$ \\
\hline
\end{tabular}

IQR inter quartile range, $O R$ odds ratio, $C I$ confidence interval, NS not selected for logistic regression analyses because $P>0.2$ in Table 2

${ }^{a} \mathrm{CD} 4$ count $<350$ cells/ $\mu \mathrm{L}$ was eligible for free antiretroviral therapy at the time of the study

${ }^{b}$ Ever had at least one of these clinical symptoms in the past 6 months: severe weight loss (>10\%), fever (>1 month, continuing or intermittent), chronic diarrhea

(>1 month), severe bacterial infection (e.g. pneumonia), oral candidiasis, oral leukoplakia, tuberculosis other stage III or stage IV symptoms

${ }^{*} P<0.2,{ }^{*} P<0.05,{ }^{* * *} P<0.01$

between being married and ART initiation observed among both ART eligible and ineligible MSM (using criteria in place in 2010-2011) suggest that a built-in educational or psychological counseling session would be necessary for cultivating the sense of responsibility for spouses and family among married HIV-infected MSM, which might facilitate early ART initiation. Given that the longer time from HIV diagnosis to the survey and older age was positively associated with ART initiation, greater government and community efforts to target and engage men earlier and more intensively may be effective, alongside linking recently infected MSM to HIV care for 


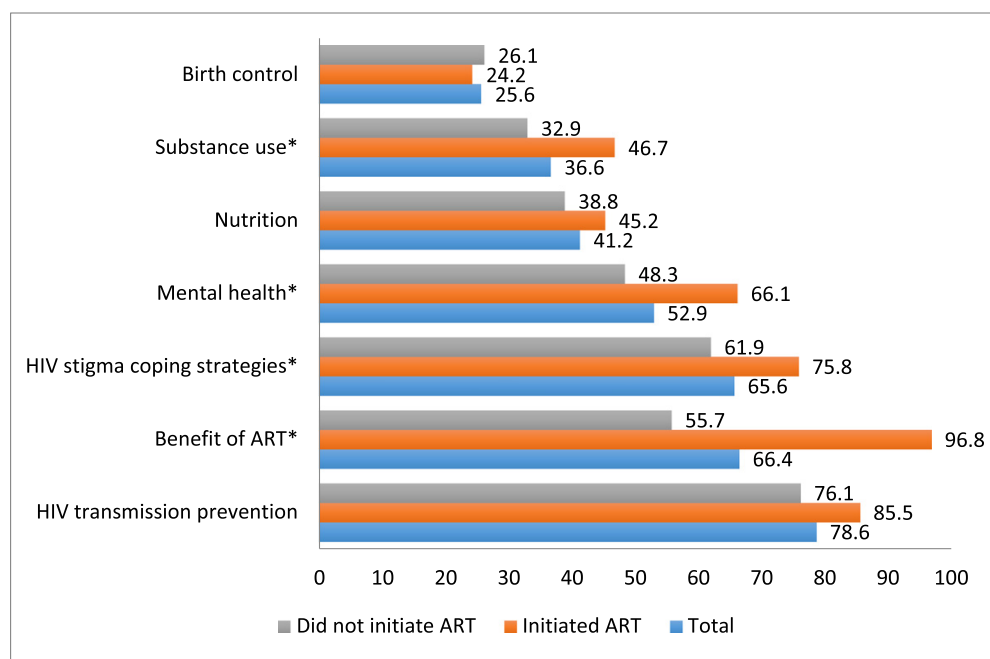

* $P<0.05$ for comparison between participants who had initiated ART and who had not.

Fig. 1 HIV care counseling services received among participants by ART initiation status

ART initiation. The benefits of legal residence (Beijing Hukou) in accessing HIV care reflect both one's ability to use local medical services and social benefits, and also one's motivation and willingness in seeking these services. People without local residence might be more financially, physically, and/or emotionally burdened as compared to local residents. In our study, having Beijing Hukou played a crucial role in ART initiation among MSM who did not meet free ART criterion. In the meantime, those who had longer duration living in Beijing demonstrated a higher likelihood of proactive ART initiation. Thus, our findings suggest the need for researching the sexual network and cooperating with local gay organizations with outreach to the migrant MSM who recently move to Beijing and/or are transiently working in Beijing.

China started its national free ART program in 2003 [28]. This program has significantly reduced mortality among HIV-infected individuals [29, 30]. However, our study showed that only $26 \%$ HIV-infected participants who had been infected with HIV for a median 15 months (IQR, 6-31) initiated ART, and the rate was lower than other risk groups in China [31-33] and MSM in other countries [34-38]. Men who met treatment criteria (36.7\%) were more likely to initiated ART than those who did not $(17.8 \%)$, but both were quite low. Our study examined ART initiation among Chinese for the first time. Previous surveys suggested considerable willingness to receive ART [13,39], yet this willingness seems not translating into uptake of ART, where studies revealed low ART use [14, 40-42]. There are multiple reasons for low ART use. First, Chinese free ART program were originally developed to provide "Four Free and One Care" (free ARV drugs, free prevention of mother-to-child transmission, free voluntary counseling and testing, free schooling for children orphaned by AIDS, and care to people living with HIV/AIDS) to HIV-infected former plasma donors and persons who injected drugs and their family members. Chinese government has vigorously promoted ART use in these populations [43]. In contrast, the promotion activities of ART use among HIV-infected MSM were sporadic prior to 2011, mainly through programs funded by international agencies such as Global Fund for AIDS and Gates Foundation. HIV-infected MSM might not be aware that they can also use the Chinese free ART program. Second, the HIV epidemic among Chinese MSM is more recent compared with those in other risk groups. Although prevention-oriented intervention programs exist for Chinese MSM, ART is relatively new and therefore unfamiliar to many [44]. Third, the majority of HIV-infected MSM are generally young ( $<40$ years), well educated, and living in large cities, so they are well accessible to HIV-related knowledge and information. They are concerned about side-effects of first-line generic ARVs in the Chinese free ART program and possible drug resistance due to failure in treatment adherence; they are concerned about no alternative drugs due to the limited number of available antiretroviral drugs (ARVs) in Chinese ART program [45-47]. Fourth, Chinese MSM face dual stigma of HIV and homosexuality, and they may encounter discrimination from the community and healthcare providers, which prevents them from seeking HIV care and treatment [48-50]. Last, the stricter eligibility criteria in earlier years might also exclude some MSM from treatment. China ART program relaxed its criteria to CD4 count $<500$ cells $/ \mu \mathrm{L}$ in 2013 . Actually in some cities, 
HIV-infected individuals can start ART immediately at diagnosis, like do in high income countries [51-53].

We recognized the limitations of our study: (1) With a relatively small sample of HIV-infected Chinese MSM living in Beijing, findings may not represent very precise estimates or be generalizable to other settings; (2) Data on socio-demographic characteristics, risky behaviors, and some clinical factors were based on self-reporting, subjecting these data to recall and social desirability biases; (3) In this cross-sectional study, we were not able to ascertain some key information, such as the exact time of ART initiation, and viral load or other markers for viral replication or immune activation at HIV diagnosis or ART initiation. These factors might also affect the physician's decision on prescribing ART. However, the main criteria for ART initiation are based on CD4 count and WHO clinical staging, but not on HIV viral load according to Chinese ART protocol.

\section{Conclusions}

In conclusion, the rates of ART initiation among Chinese MSM were low as of 2011. Compared to other subgroups, HIV-infected Chinese MSM are less likely to initiate ART. This is the first study in China to investigating factors associated with ART initiation in this marginalized population. Policy changes for expanding ART eligibility and interventions to improve the continuum of HIV care are in progress in China. Impact evaluations can help assess continuing barriers to ART initiation among MSM.

\section{Abbreviations \\ ART: Antiretroviral therapy; ARV: Antiretroviral; MSM: Men who have sex with men; WHO: World Health Organization; STD: Sexually transmitted diseases; ELISA: Enzyme-linked immunosorbent assay; WB: Western blot; RPR: Rapid plasma reagin.}

\section{Competing interests}

The authors declare that they have no competing interests.

\section{Authors' contribution}

HZQ conceived of the study; YR, SHV, YS and HZQ participated in its design and coordination; YL, CYO, PW, YJ and HZQ performed the statistical analysis; $Y L$ and HZQ drafted the manuscript; YR, SHV, CYO, PW, YJ and YS revised the manuscript; All authors read and approved the final manuscript.

\section{Acknowledgements}

This study was supported by the Vanderbilt Clinical \& Translational Research Scholars (VCTRS) Program (UL1TR000445 and KL2TR000446), and in part, by grants from the U.S. National Institutes of Health (R01Al094562), the Ministry of Science and Technology of China (2012ZX10004-904, 2012ZX10001-002), the Chinese State Key Laboratory for Infectious Disease (Development Grant 2012SKLID103), and the National Natural U.S. National Institutes of Health Science Foundation of China (81273188)

\section{Author details}

${ }^{1}$ Vanderbilt Institute for Global Health, Vanderbilt University School of Medicine, Nashville, Tennessee, USA. ${ }^{2}$ State Key Laboratory of Infectious Disease Prevention and Control (SKLID), Collaborative Innovation Center for Diagnosis and Treatment of Infectious Diseases, Chinese Center for Disease Control and Prevention (China CDC), Beijing, China. ${ }^{3}$ Department of Pediatrics, Vanderbilt University School of Medicine, Nashville, Tennessee, USA. ${ }^{4}$ Department of Medicine, Vanderbilt University School of Medicine,
Nashville, Tennessee, USA. ${ }^{5}$ Department of Biomedical Informatics, Vanderbilt University School of Medicine, Nashville, Tennessee, USA. ${ }^{6}$ Department of Biostatistics, Vanderbilt University School of Medicine, Nashville, Tennessee, USA.

Received: 9 June 2015 Accepted: 3 December 2015

Published online: 15 December 2015

\section{References}

1. Mugavero MJ, Amico KR, Horn T, Thompson MA. The state of engagement in HIV care in the United States: from cascade to continuum to control. Clin Infect Dis. 2013;57(8):1164-71.

2. Gardner EM, McLees MP, Steiner JF, Del Rio C, Burman WJ. The spectrum of engagement in HIV care and its relevance to test-and-treat strategies for prevention of HIV infection. Clin Infect Dis. 2011;52(6):793-800.

3. Cohen MS, Chen YQ, McCauley M, Gamble T, Hosseinipour MC, Kumarasamy N, et al. Prevention of HIV-1 infection with early antiretroviral therapy. N Engl J Med. 2011;365(6):493-505.

4. Vermund SH, Hayes RJ. Combination prevention: new hope for stopping the epidemic. Curr HIV/AIDS Rep. 2013;10(2):169-86.

5. Fang CT, Hsu HM, Twu SJ, Chen MY, Chang YY, Hwang JS, et al. Decreased HIV transmission after a policy of providing free access to highly active antiretroviral therapy in Taiwan. J Infect Dis. 2004;190(5):879-85.

6. Wood E, Kerr T, Marshall BD, Li K, Zhang R, Hogg RS, et al. Longitudinal community plasma HIV-1 RNA concentrations and incidence of HIV-1 among injecting drug users: prospective cohort study. BMJ. 2009:338:b1649.

7. Tanser F, Barnighausen T, Grapsa E, Zaidi J, Newell ML. High coverage of ART associated with decline in risk of HIV acquisition in rural KwaZulu-Natal. South Africa Sci. 2013;339(6122):966-71.

8. Das M, Chu PL, Santos GM, Scheer S, Vittinghoff E, McFarland W, et al. Decreases in community viral load are accompanied by reductions in new HIV infections in San Francisco. PLoS One. 2010;5(6):e11068.

9. Grinsztejn B, Hosseinipour MC, Ribaudo HJ, Swindells S, Eron J, Chen YQ, et al. Effects of early versus delayed initiation of antiretroviral treatment on clinical outcomes of HIV-1 infection: results from the phase 3 HPTN 052 randomised controlled trial. Lancet Infect Dis. 2014;14(4):281-90.

10. Gill VS, Lima VD, Zhang W, Wynhoven B, Yip B, Hogg RS, et al. Improved virological outcomes in British Columbia concomitant with decreasing incidence of HIV type 1 drug resistance detection. Clin Infect Dis. 2010;50(1):98-105.

11. Zhu H, Napravnik S, Eron J, Cole S, Ma Y, Wohl D, et al. Attrition among human immunodeficiency virus (HIV)- infected patients initiating antiretroviral therapy in China, 2003-2010. PLoS One. 2012;7(6):e39414.

12. Zhang $F$, Dou Z, Ma Y, Zhang Y, Zhao Y, Zhao D, et al. Effect of earlier initiation of antiretroviral treatment and increased treatment coverage on HIV-related mortality in China: a national observational cohort study. Lancet Infect Dis. 2011;11(7):516-24.

13. Jiang $H H$, Lu F, He HJ, Zhang DD, Zeng G, Xu P, et al. Acceptability status of early antiretroviral therapy among HIV-positive men who have sex with men. Zhonghua Yu Fang Yi Xue Za Zhi. 2013;47(9):843-7.

14. Wu Z, Xu J, Liu E, Mao Y, Xiao Y, Sun X, et al. HIV and syphilis prevalence among men who have sex with men: a cross-sectional survey of 61 cities in China. Clin Infect Dis. 2013:57(2):298-309.

15. Zhou Y, Li D, Lu D, Ruan Y, Qi X, Gao G. Prevalence of HIV and syphilis infection among men who have sex with men in China: a meta-analysis. Biomed Res Int. 2014;2014:620431.

16. State Council AIDS Working Committee Office (SCAWCO): China 2012 UNGASS Country Progress Report.Beijing, China: Ministry of Health of the People's Republic of China; 2012. http:/www.unaids.org/sites/default/files/ country/documents//file,68497,es.pdf, Accessed 13 Mar 2015.

17. State Council AIDS Working Committee Office (SCAWCO):China 2014 UNGASS Country Progress Report.Beijing, China: Ministry of Health of the People's Republic of China; 2014. http://www.unaids.org/sites/default/files/ documents/CHN narrative report_2014.pdf Accessed 13 Mar 2015.

18. Ruan Y, Pan SW, Chamot E, Qian HZ, Li D, Li QC, et al. Sexual mixing patterns among social networks of HIV-positive and HIV-negative Beijing men who have sex with men: a multilevel comparison using roundtable network mapping. AIDS Care. 2011;23(8):1014-25.

19. He Q, Wang Y, Lin P, Liu Y, Yang F, Fu X, et al. Potential bridges for HIV infection to men who have sex with men in Guangzhou, China. AIDS Behav. 2006;10(4 Suppl):S17-23. 
20. Chow EP, Jing J, Feng Y, Min D, Zhang J, Wilson DP, et al. Pattern of HIV testing and multiple sexual partnerships among men who have sex with men in China. BMC Infect Dis. 2013;13:549.

21. Wei C, Yan H, Yang C, Raymond HF, Li J, Yang H, et al. Accessing HIV testing and treatment among men who have sex with men in China: a qualitative study. AIDS Care. 2014;26(3):372-8.

22. Liu Y, Qian HZ, Ruan Y, Yin L, Ma J, Dahiya K, et al. Alcohol use among Chinese men who have sex with men: an epidemiological survey and meta-analysis. Biomed Res Int. 2014;2014:414381.

23. Qian HZ, Ruan Y, Liu Y, Milam DF, HM LS, Yin L, et al. Lower HIV risk among circumcised men who have sex with men in China: Interaction with anal sex role in a cross-sectional study. Journal of acquired immune deficiency syndromes. 2015.

24. Hu Y, Qian HZ, Sun J, Gao L, Yin L, Li X, et al. Anal human papillomavirus infection among HIV-infected and uninfected men who have sex with men in Beijing, China. J Acquir Immune Defic Syndr. 2013;64(1):103-14.

25. Blank MB, Himelhoch SS, Balaji AB, Metzger DS, Dixon LB, Rose CE, et al A multisite study of the prevalence of HIV with rapid testing in mental health settings. Am J Public Health. 2014;104(12):2377-84.

26. Zala C, Rustad CA, Chan K, Khan NI, Beltran M, Warley E, et al. Determinants of treatment access in a population-based cohort of HIV-positive men and women living in Argentina. Medscape J Med. 2008;10(4):78.

27. Tao J, Ruan Y, Yin L, Vermund SH, Shepherd BE, Shao Y, et al. Sex with women among men who have sex with men in China: prevalence and sexual practices. AIDS Patient Care STDS. 2013;27(9):524-8.

28. Zhang F, Haberer JE, Wang Y, Zhao Y, Ma Y, Zhao D, et al. The Chinese free antiretroviral treatment program: challenges and responses. AIDS. 2007;21 Suppl 8:S143-8.

29. Zhang F, Dou Z, Yu L, Xu J, Jiao JH, Wang N, et al. The effect of highly active antiretroviral therapy on mortality among HIV-infected former plasma donors in China. Clin Infect Dis. 2008;47(6):825-33.

30. Zhang F, Dou Z, Ma Y, Zhao Y, Liu Z, Bulterys M, et al. Five-year outcomes of the China National Free Antiretroviral Treatment Program. Ann Intern Med. 2009;151(4):241-51. W-252.

31. Xing $H$, Ruan $Y$, Li J, Shang $H$, Zhong $P$, Wang $X$, et al. HIV drug resistance and its impact on antiretroviral therapy in Chinese HIV-infected patients. PLoS One. 2013;8(2):e54917.

32. Luo X, Duan S, Duan Q, Pu Y, Yang Y, Ding Y, et al. Tobacco use among HIV-infected individuals in a rural community in Yunnan Province, China. Drug Alcohol Depend. 2014;134:144-50.

33. Muessig KE, McLaughlin MM, Nie JM, Cai W, Zheng H, Yang L, et al. Suboptimal antiretroviral therapy adherence among HIV-infected adults in Guangzhou, China. AIDS Care. 2014;26(8):988-95.

34. Ferro EG, Weikum D, Vagenas P, Copenhaver MM, Gonzales P, Peinado J, et al. Alcohol use disorders negatively influence antiretroviral medication adherence among men who have sex with men in Peru. AIDS Care. 2015;27(1):93-104

35. Raymond HF, Chen YH, Ick T, Scheer S, Bernstein K, Liska S, et al. A new trend in the HIV epidemic among men who have sex with men, San Francisco, 2004-2011. J Acquir Immune Defic Syndr. 2013;62(5):584-9.

36. Hidalgo-Tenorio C, Rivero-Rodriguez M, Gil-Anguita C, Lopez De Hierro M, Palma P, Ramirez-Taboada J, et al. Antiretroviral therapy as a factor protective against anal dysplasia in HIV-infected males who have sex with males. PLoS One. 2014;9(3):e92376.

37. Paz-Bailey G, Pham H, Oster AM, Lansky A, Bingham T, Wiegand RE, et al. Engagement in HIV care among HIV-positive men who have sex with men from 21 cities in the United States. AIDS Behav. 2014;18 Suppl 3:348-58.

38. Graham SM, Mugo P, Gichuru E, Thiong'o A, Macharia M, Okuku HS, et al. Adherence to antiretroviral therapy and clinical outcomes among young adults reporting high-risk sexual behavior, including men who have sex with men, in coastal Kenya. AIDS Behav. 2013;17(4):1255-65.

39. Zhang Q, Tang Z, Sun H, Cheng P, Qin Q, Fan Y, et al. Acceptability of early anti-retroviral therapy among HIV-infected people in Anhui province in China. AIDS Care. 2014;27:1-6.

40. Rodriguez-Arenas MA, Jarrin I, del Amo J, Iribarren JA, Moreno S, Viciana P, et al. Delay in the initiation of HAART, poorer virological response, and higher mortality among HIV-infected injecting drug users in Spain. AIDS Res Hum Retroviruses. 2006;22(8):715-23.

41. Wu YL, Yang HY, Wang J, Yao H, Zhao X, Chen J, et al. Prevalence of suicidal ideation and associated factors among HIV-positive MSM in Anhui, China. Int J STD AIDS. 2014;26(7):496-503.
42. Liao M, Kang D, Tao X, Bouey JH, Aliyu MH, Qian Y, et al. Alcohol use, stigmatizing/discriminatory attitudes, and HIV high-risk sexual behaviors among men who have sex with men in China. Biomed Res Int. 2014;2014: 143738.

43. Choi KH, Lui H, Guo Y, Han L, Mandel JS. Lack of HIV testing and awareness of HIV infection among men who have sex with men, Beijing, China. AIDS Educ Prev. 2006;18(1):33-43.

44. Zhang L, Zhang D, Yu B, Wang S, Liu Y, Wang J, et al. Prevalence of HIV infection and associated risk factors among men who have sex with men (MSM) in Harbin, P R China. PLoS One. 2013;8(3):e58440.

45. Wang $X$, Wu Z . Factors associated with adherence to antiretroviral therapy among HIV/AIDS patients in rural China. AIDS. 2007;21 Suppl 8:S149-55.

46. Johnson MO, Dilworth SE, Taylor JM, Neilands TB. Improving coping skills for self-management of treatment side effects can reduce antiretroviral medication nonadherence among people living with HIV. Ann Behav Med. 2011;41(1):83-91.

47. Dou Z, Chen RY, Xu J, Ma Y, Jiao JH, Durako S, et al. Changing baseline characteristics among patients in the China National Free Antiretroviral Treatment Program, 2002-09. Int J Epidemiol. 2010;39 Suppl 2:ii56-64.

48. Grossman AH. Gay men and HIV/AIDS: understanding the double stigma. J Assoc Nurses AIDS Care. 1991;2(4):28-32.

49. Feng $Y$, Wu Z, Detels R. Evolution of men who have sex with men community and experienced stigma among men who have sex with men in Chengdu, China. J Acquir Immune Defic Syndr. 2010;53 Suppl 1:S98-S103.

50. Mahajan AP, Sayles JN, Patel VA, Remien RH, Sawires SR, Ortiz DJ, et al. Stigma in the HIV/AIDS epidemic: a review of the literature and recommendations for the way forward. AIDS. 2008;22 Suppl 2:567-79.

51. Hsu LC, Truong HH, Vittinghoff E, Zhi Q, Scheer S, Schwarcz S. Trends in Early Initiation of Antiretroviral Therapy and Characteristics of Persons With HIV Initiating Therapy in San Francisco, 2007-2011. J Infect Dis. 2014;209(9): 1310-4.

52. Cuzin L, Delpierre C, Yazdanpanah Y, Lert F. How long do physicians wait to start antiretroviral treatment in newly diagnosed HIV-infected patients? HIV Clin Trials. 2011;12(6):339-42.

53. Thompson MA, Aberg JA, Cahn P, Montaner JS, Rizzardini G, Telenti A, et al. Antiretroviral treatment of adult HIV infection: 2010 recommendations of the International AIDS Society-USA panel. JAMA. 2010;304(3):321-33.

\section{Submit your next manuscript to BioMed Central and we will help you at every step:}

- We accept pre-submission inquiries

- Our selector tool helps you to find the most relevant journal

- We provide round the clock customer support

- Convenient online submission

- Thorough peer review

- Inclusion in PubMed and all major indexing services

- Maximum visibility for your research

Submit your manuscript at www.biomedcentral.com/submit
BioMed Central 